\title{
SUBSTANTIATION OF THE METHOD OF MEAT SAMPLE PREPARATION FOR INSTRUMENTAL DETERMINATION OF CONSISTENCY
}

\author{
Kirill I. Spiridonov, Victoria V. Nasonova*, Elena K. Tunieva \\ V.M. Gorbatov Federal Research Center for Food Systems of Russian Academy of Sciences, Moscow, Russia
}

Key words: consistency, pork, beef, sample preparation, shear stress

\begin{abstract}
In recent years, there has been a transformation in the choice and lifestyle of Russian citizens. An increasing part of the population makes a more reasonable choice, taking into account all aspects, including the most important for meat products - these are organoleptic characteristics, in particular the consistency of the product. Consumers prefer products with the delicate, soft texture, expect good "biteness» and "cheweness». Therefore, preference is given to tender, juicy meat with a low content of connective tissue. The most commonly used method for testing meat consistency in laboratories around the world is a method that uses strength testing machines with a Warner-Bratzler blade (WB blade). In this work, the Shimadzu AGS-1kN universal testing machine (Japan) was chosen for research. Samples obtained from l. dorsi of pork and beef were selected as meat raw materials. To determine the optimal and reproducible method of sample preparation, some of them were subjected to heat treatment before analysis. In the study of samples without heat treatment, deviations from the average were more than $11 \%$. After meat was cooked, a decrease in the relative standard deviation of the maximum shear stress from the average was achieved: from 11\% in raw meat to $5 \%$ in a pork sample and $5.3 \%$ in a beef sample. The heat treatment of pre-cut samples led to a change in their geometric shape, which created additional difficulties for obtaining correct results, and also negatively affected the increase in the relative deviation to $15.5 \%$ for beef.
\end{abstract}

\section{Introduction}

Despite an emergent decline in meat product output over the first six months of 2019, producers should make efforts to retain their consumers. In recent years, a choice and lifestyle of the Russian citizens have been transformed. An increasing proportion of the population makes a more reasonable choice that takes into consideration all aspects, including those that are the most important for meat products - organoleptic characteristics, in particular, product consistency. This is confirmed by the results of investigations performed by foreign scientists who demonstrated that one of the main meat quality indicators noted by consumers was tender [1]

Based on consumer preferences, producers and developers of meat products have begun to pay more attention to formation of tender consistency of a finished product. At the same time, it was found that methodological approaches to objective assessment of meat and meat product consistency as well instrumental product characteristics in existing regulatory documents were absent. Analysis of scientific-technical literature allowed revealing several criteria for assessment of meat product consistency. Ball et al. made attempts to present meat consistency as a complex of two sensations: visual — «sight» and tactile — «feel». They meant by the term «sight» that meat consistency is the macroscopic peculiarities of muscle tissue in terms of smoothness or fineness of grain. It was suggested that consistency depends on a size of fiber bundles: the smaller bundles, the better consistency. On this basis, this assessment was applicable both to raw and cooked samples.
On the contrary, the term «feel» could be applied only to ready-to-eat samples as product consistency was regarded as the feel of smoothness or fineness of muscle tissue in the mouth during product chewing [2].

Later on, it was found that assessment of consistency only by a size of muscle fibers and/or bundles of muscle fibers seen on the cross section of the surface was not objective. Meat consistency depends on a complex of different characteristics and factors. Both lifetime aspects (such as age, breed, gender and diet of animals, type of muscles and anatomic location) and several technological factors (for example, the use of electrical stimulation, a method of processing) affect consistency [3]. Consumers prefer products with tender, soft consistency, and expect good «biteness» and «cheweness» [4]. Therefore, preference is given to tender and juicy meat with an insignificant content of connective tissue [5].

The most common method for investigation of meat consistency in laboratories of the whole world is a method that uses the strength testing machines with the WarnerBratzler blade (WB-blade). The principle of this method is based on modeling of food product chewing [6]. It was developed by Lyman Bratzler in 1932, and already since the 1950s, this method has been used worldwide. Due to good reproducibility of results, this method can be used for detection of hardness and tenderness of meat products. It is also intended for detailed analysis, for example, for studying dependencies associated with used methods of selection and their effect on the ultimate meat quality $[7,8]$. At the same time, an absence of the standardized methodological 
approach does not allow obtaining comparable results in different laboratories. It is the process of sample preparation that is of great importance in this case.

\section{Materials and methods}

The universal testing machine Shimadzu AGS-1kN (Japan) was chosen for experiments. The method is based on WB-blade passing across the fibers of a sample, which has a shape of a parallelepiped with a length of $50 \mathrm{~mm}$, width and height of $20 \mathrm{~mm}$. The blade speed was $50 \mathrm{~mm} / \mathrm{min}$. The force was registered with a strain gauge. The obtained results were presented in TrapeziumLite X software and subjected to statistical processing.

The samples of l. dorsi from pork and beef were chosen as meat raw materials. To determine an optimal and reproducible method of sample preparation, some of the samples were subjected to heat treatment before analysis. Heat treatment was carried out by cooking in a water bath at a constant temperature of $80^{\circ} \mathrm{C}$ until reaching a core temperature of $72 \pm 1^{\circ} \mathrm{C}$ by two methods:

1. using a whole piece with following cooling and excision of a sample, which had a shape of parallelepiped with a length of $50 \mathrm{~mm}$, width and height of $20 \mathrm{~mm}$.

2. cooking a preliminary excized sample, which had a shape of parallelepiped with a length of $50 \mathrm{~mm}$, width and height of $20 \mathrm{~mm}$.

Meat consistency was assessed by a value of maximum shear stress, which accounts for the geometrical shape of samples and Warner-Bratzler blade width (equation 1).
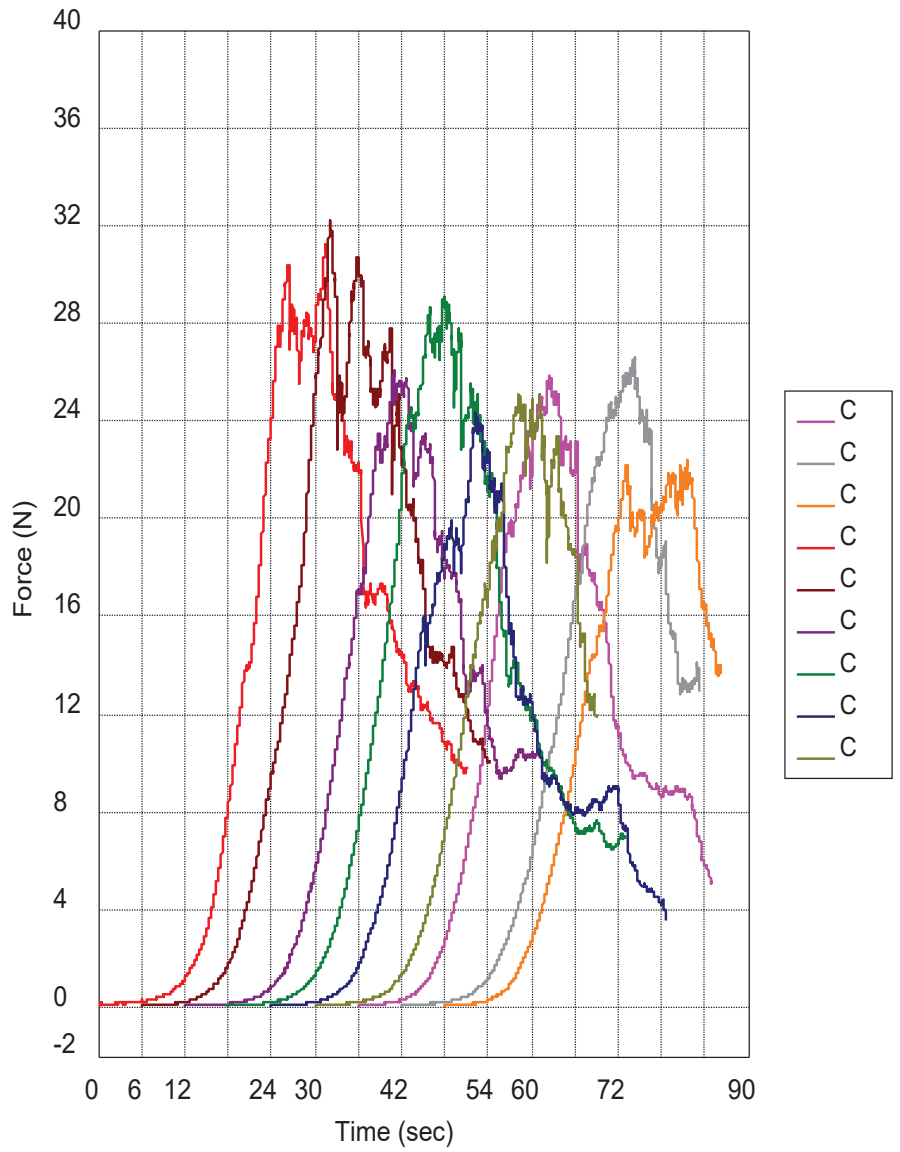

Figure 1. Dynamics of the shear force change during pork sample cutting where:

$$
Q=F / S \times k
$$

$Q$ - maximum shear stress, $\mathrm{N} / \mathrm{m}^{2}$,

$F$ - maximum shear force, $\mathrm{N}$,

$k=0,0015$ - coefficient accounting for Warner-Bratzler blade width.

\section{Results and discussion}

At the first stage, maximum shear stress of the control samples, which were not subjected to heat treatment, was determined. The obtained results are presented in Figure 1 and Figure 2 and in Table 1, respectively.

Table 1. Mean value of maximum shear stress of pork (C) and beef $(\mathrm{Cb})$ samples without heat treatment

\begin{tabular}{|c|c|}
\hline Sample & Mean value of shear stress, Pa \\
\hline Pork (C) & $101.2 \pm 11.3$ \\
\hline Pork (C) & $105.1 \pm 11.5$ \\
\hline
\end{tabular}

The results suggest that the obtained values for both samples are in quite a close range. However, in both cases the observed measurement results indicated a rather large deviation between samples: from 120.9 to $84.1 \mathrm{~Pa}$ for pork and from 130.6 to $84.0 \mathrm{~Pa}$ for beef. The obtained deviations can be explained by the morphological structure of meat raw materials, its heterogeneity, the presence of connective and fatty tissues besides muscle fibers. Connective tissue has high strength and when it comes to the cutting edge of the Warner-Bratzler blade during analysis, it shows much higher

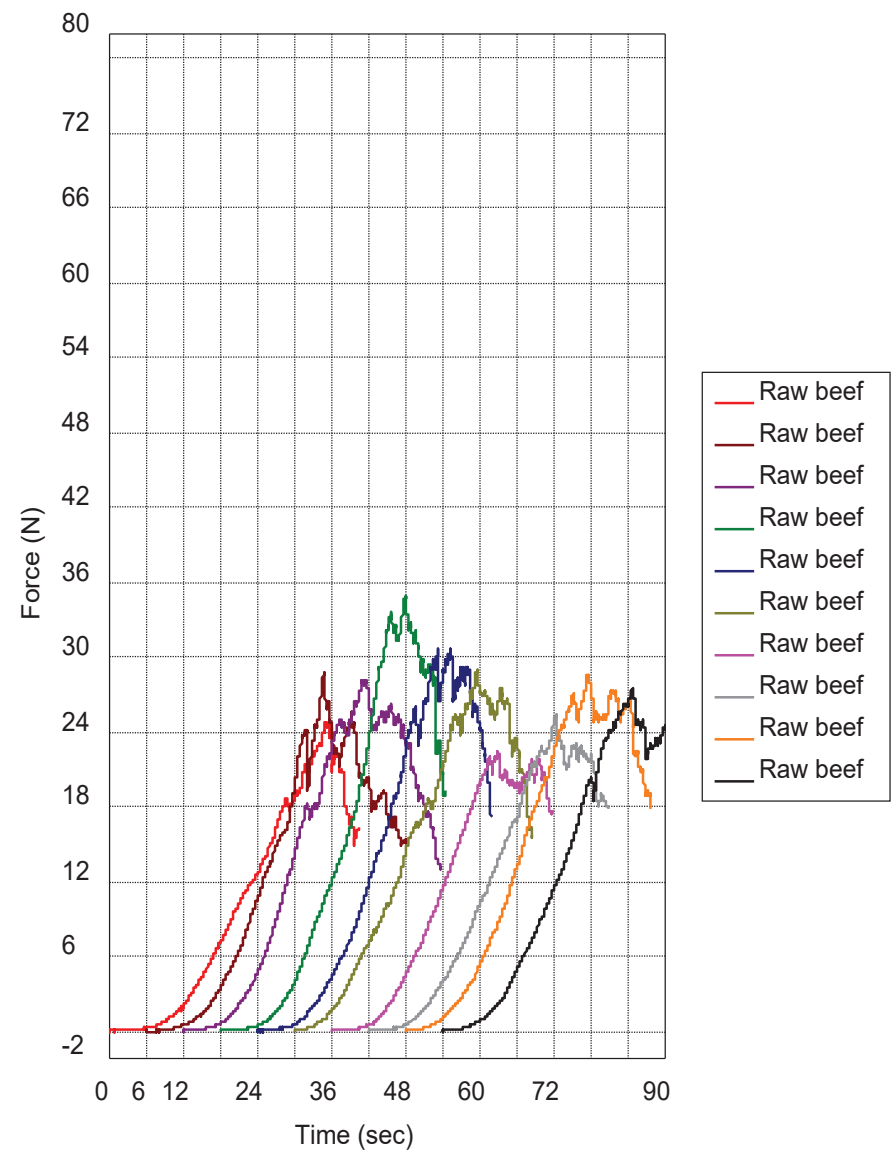

Figure 2. Dynamics of the shear force change during beef sample cutting 
resistance to cutting than muscle tissue. In the analysis of the uncooked samples, therefore, deviations from the mean value can be more than $11 \%$ provided that one of the most homogeneous muscle in the cut ( $m$. longissimus) was chosen for an experiment. This large deviation does not allow making a statement about objectivity of a method and reproducible results. At the same time, virtually identical results for uncooked samples from different meat raw materials (pork and beef) does not enable meat differentiation by type of farm animals using this method, while it is acknowledged that cooked beef is tougher than pork.

Taking into consideration the obtained results, the strength properties of meat raw materials after cooking were studied. Cooking was chosen as the most common method of heat treatment. To determine a method of sample preparation before or after heat treatment, two different sequences of steps were used: heat treatment followed by sample excision or, vice versa, a sample was excised from a whole piece and then cooked.

The results of ten parallel measurements of maximum shear stress for cooked pork samples are presented in Figure 3 (sample 1.1 - the pork sample excised from the cooked whole piece, sample 1.2 - the pork sample excised from the raw whole piece and then cooked).

It is worth noting that the mean of maximum shear stress in the sample cooked in the cut form (1.2) was almost twice as high as the mean in sample 1.1: 114.4 Pa for sample 1.1 and $239.2 \mathrm{~Pa}$ for sample 1.2, respectively. It can be explained by the structure and technological characteristics of meat raw materials. However, most significant is the fact that a reduction in the relative standard deviation of the values of maximum shear stress from the mean was achieved: from $11 \%$ in raw meat to $5 \%$ in sample 1.1 and $8.2 \%$ in sample 1.2 .

The similar picture was observed for the studied beef samples (Figure 4). Beef sample 3.1 was prepared in much the same way as sample 1.1, sample 3.2 as sample 1.2.

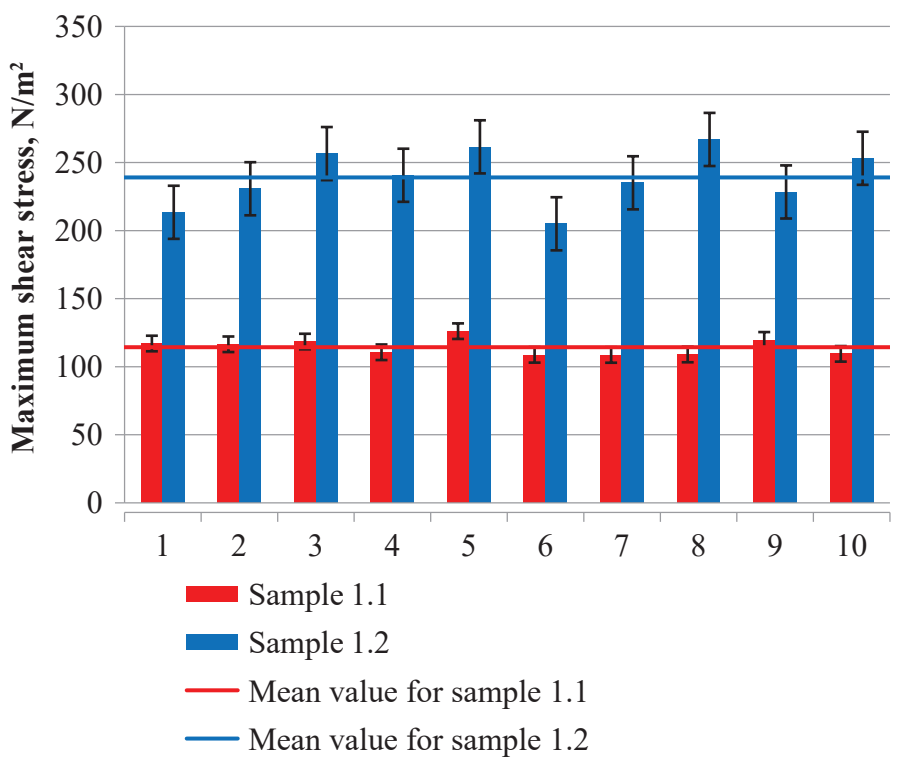

Figure 3. Results of maximum shear stress measurement in cooked pork samples
It is worth noting that in both cases the beef samples became tougher: the mean value of maximum shear stress increased from 105.1 $\mathrm{Pa}$ in raw meat to $198.1 \mathrm{~Pa}$ in sample 3.1 and to $239.5 \mathrm{~Pa}$ in sample 3.2. This result was expected as beef toughness always strongly increases after heat treatment. The relative value of deviation in the case of sample 3.1 was $5.3 \%$, which was very close to the result in pork. In the case of sample 3.2, the relative deviation increased from $11 \%$ to $15.5 \%$.

Therefore, the following conclusions can be made.

When a sample was excised from a cooked piece, the value of maximum shear stress after pork heat treatment insignificantly exceeded the similar value in raw meat 114.4 $\mathrm{Pa}$ and 101.2 Pa, respectively. However, heat treatment allowed reducing the value of relative deviation in parallel sections from 11 to $5 \%$, increasing reproducibility of results; preliminary excision of samples from raw meat and their following cooking increased the value of maximum shear stress almost twice up to $239.2 \mathrm{~Pa}$ upon an insignificant decrease in relative deviation up to $8.2 \%$.

The differences were even more significant in beef: after cooking and following excision of a sample, the results of maximum shear stress were twice as high as the similar value in raw meat: 198.1 and 105.1 Pa. Moreover, the value of relative deviation decreased from 11 to $5.3 \%$ similar to what was observed in pork.

\section{Conclusions}

According to the obtained data, it is not recommended to analyze texture of meat samples by the method of maximum shear stress measurement using the Warner-Bratzler blade on meat raw material samples without preliminary heat treatment. The values of shear stress in raw meat samples had higher standard deviations (more than 11\%). In addition, determination of the shear stress value in raw meat does not allow muscle tissue differentiation by animal species.

For correct sample preparation, it is recommended to apply initial heat treatment of a whole meat piece by cooking

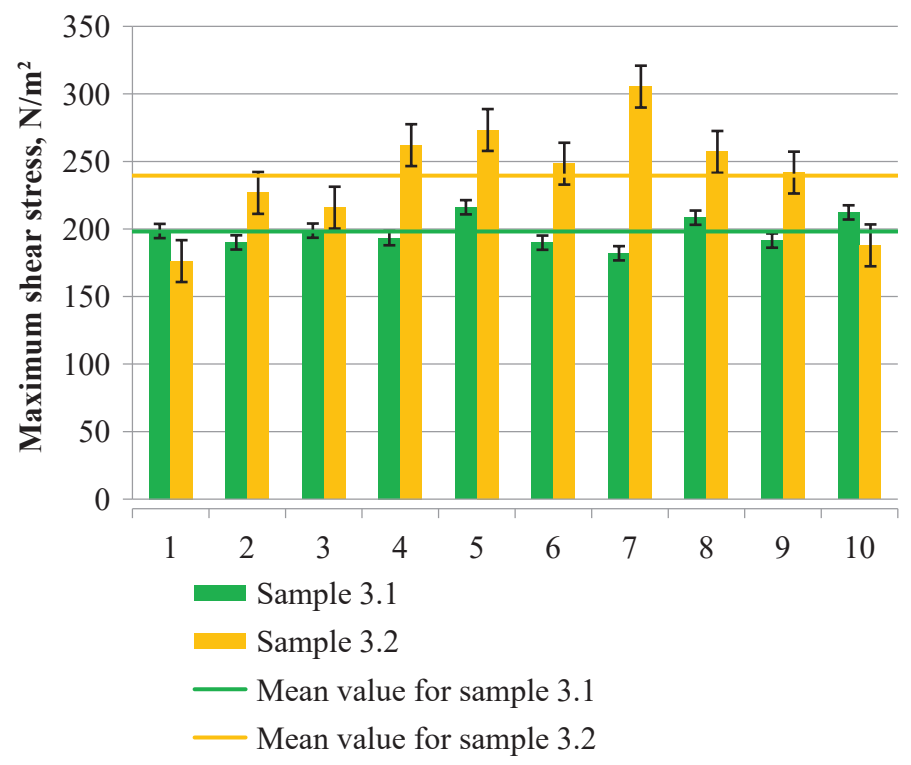

Figure 4. Results of maximum shear stress measurement in cooked beef samples 
in a vacuum package up to a core temperature of $72 \pm 1^{\circ} \mathrm{C}$, and then to excise a sample of a necessary geometric shape. This preparation of samples will allow obtaining the lowest values of relative deviations both for pork and beef: 5 and $5.3 \%$, respectively.
Heat treatment of preliminary excised samples led to changes in their geometric shape, which created additional difficulties for obtaining correct results, and also negatively affected an increase in the value of relative deviation to $15.5 \%$ for beef.

\section{REFERENCES}

1. Szczesniak, A. S. (1986). Sensory texture evaluation methodology. In Proceedings of the 39th Annual Reciprocal Meat Conference of the American Meat Science Association, Chicago, IL: National Livestock and Meat Board, 39, 86-96.

2. Aberle, E.D., Forrest J.C., Gerrard D.E., Mills E.W. (2001). Principles of Meat Science. 4th ed. Kendall/Hunt Publishing Company; Dubuque, IA, USA. -376 p. ISBN 0787247200

3. Ball, C.O., Clauss, H.E., Stier, E.F. (1957). Factors affecting quality of prepackaged meat: Loss of weight and study of texture. Food Technology, 11, 281-284.

4. Zheng, L., Da-Wen Sun, D.-W., Tan, J. (2008). Quality evaluation of meat cuts. Book Chapter in Computer Vision Technology for Food Quality Evaluation, 111-138. DOI: 10.1016/B978012373642-0.50008-9

5. Behrends, J.M., Goodson, K.J., Koohmaraie, M., Shackelford, S.D., Wheeler, T.L., Morgan, W.W., Reagan, J.O., Gwartney, B.L., Wise, J.W., Savell, J.W. (2005). Beef customer satisfaction: USDA quality grade and marination effects on consumer evaluations of top round steaks. Journal of Animal Science, 83, 662-670.

6. Lyford, C., Thompson, J., Polkinghoresiane, R., Miller, M., Nishimura, T., Neath, K., Allen, P., Belasco, E., Lyford, C. (2010). Is willingness to pay (WTP) for beef quality grades affected by consumer demographics and meat consumption preferences. Australasian Agribusiness Review, 18, 1-17.

7. Destefanis, G., Brugiapaglia, A., Barge, M.T., Dal Molin, E. (2008). Relationship between beef consumer tenderness perception and Warner-Bratzler shear force. Meat Science, 78(3), 153156. DOI: 10.1016/j.meatsci.2007.05.031

8. Novaković, S., Tomašević, I. (2017). A comparison between Warner-Bratzler shear force measurement and texture profile analysis of meat and meat products: $A$ review. IOP Conference Series: Earth and Environmental Science, 85(1), 012063. DOI: 10.1088/1755-1315/85/1/012063

\section{AUTHOR INFORMATION}

Kirill I. Spiridonov - candidate of technical sciences, senior research scientist, V.M. Gorbatov Federal Research Center for Food Systems of Russian Academy of Sciences.109316, Moscow, Talalikhina str., 26. Tel: +7-495-676-71-11. E-mail: k.spiridonov@fncps.ru

Victoria V. Nasonova - candidate of technical sciences, chef of department, V.M. Gorbatov Federal Research Center for Food Systems of Russian Academy of Sciences.109316, Moscow, Talalikhina str., 26. Tel.: +7-495-676-65-51, E-mail: v.nasonova@fncps.ru

${ }^{*}$ corresponding author

Elena K. Tunieva - candidate of technical sciences, leading research scientist, V.M. Gorbatov Federal Research Center for Food Systems of Russian Academy of Sciences.109316, Moscow, Talalikhina str., 26. Tel.: +7-495-676-71-11, E-mail: e.tunieva@fncps.ru

Authors are equally relevant to the writing of the manuscript, and equally responsible for plagiarism

The authors declare no conflict of interest

Received 21.05.2019 Accepted in revised 08.09.2019 Accepted for publication 25.09.2019 